\title{
Effectiveness of Dyes Removal by Mixed Fungal Cultures and Toxicity of Their Metabolites
}

\author{
Wioletta Przystaś • Ewa Zablocka-Godlewska • \\ Elżbieta Grabińska-Sota
}

Received: 28 November 2012 / Accepted: 20 March 2013 /Published online: 6 April 2013

(C) The Author(s) 2013. This article is published with open access at Springerlink.com

\begin{abstract}
Decolorization of brilliant green $(0.06 \mathrm{~g} / \mathrm{L})$, Evans blue $(0.15 \mathrm{~g} / \mathrm{L})$, and their mixture (total concentration $0.08 \mathrm{~g} / \mathrm{L}$, proportion $1: 1 \mathrm{w} / \mathrm{w}$ ) by fungi was studied. Fungal strains [Pleurotus ostreatus (BWPH), Gloeophyllum odoratum (DCa), and Fusarium oxysporum (G1)] were used separately and as a mixture of them. Zootoxicity (Daphnia magna) and phytotoxicity (Lemna minor) changes were estimated after the end of experiment. Mixtures of fungal strains were less effective in decolorization process than the same strains used separately (as a single strains). After $96 \mathrm{~h}$ of experiment, living biomass of strain BWPH removed up to $95.5 \%$; DCa, up to $84.6 \%$; G1, up to $79.2 \%$ where mixtures BWPH + DCa removed up to $74.3 \%$; and BWPH + G1, only up to $32.2 \%$ of used dyes. High effectiveness of dyes removal not always corresponded with decrease of toxicity. The highest decrease of zootoxicity and phytotoxicity (from $\mathrm{V}$ to III toxicity class or to even nontoxic) was noticed for single strains, while no changes or slight toxicity decrease was noticed in samples with strains mixtures.
\end{abstract}

Keywords Mixed fungal culture $\cdot$ Dyes decolorization $\cdot$ Zootoxicity $\cdot$ Phytotoxicity

\footnotetext{
W. Przystaś $(\bowtie) \cdot$ E. Zabłocka-Godlewska •

E. Grabińska-Sota

Environmental Biotechnology Department,

Silesian University of Technology,

Akademicka 2A, 44-100 Gliwice, Poland

e-mail: wioletta.przystas@polsl.pl
}

\section{Introduction}

Consumers' expectations concerning the quality and attraction of products entail higher production and usage of dyes. Imperfection of coloring processes, washing of materials, dyes sustainability, as well as low effectiveness of conventional wastewater treatment cause environmental risk. Many of dyes are known as carcinogenic, mutagenic, and toxic substances. Their deposit causes deterioration of life conditions in the water ecosystems. They adversely affect the surface water organisms and the primary production (Banat et al. 1996; Wesenberg et al. 2003; Fu and Viraraghavan 2001; Pointing and Vrijmoed 2000; Forgacs et al. 2004).

Colored wastewaters are characterized by a large variability of composition, including type and concentration of dyes. Color reduction may be achieved by physicochemical as well as biological processes. The conventional physicochemical methods are the following: flocculation, flotation, precipitation, oxidation and reduction, ozonation, coagulation, membrane separation, and adsorption. Their effectiveness is mostly very high as well as their costs (Azmi et al. 1998; Robinson et al. 2001; Somasiri et al. 2006). In spite of the low effectiveness of decolorization by activated sludge, biological processes seem to be still an interesting alternative. There is a sequence of publications proving high potential of bacterial, fungal, and algae species in dyes removal (Banat et al. 1996; Azmi et al. 1998; Pointing and Vrijmoed 2000; Robinson et al. 2001; Fu and 
Viraraghavan 2001; Deng et al. 2008). In these processes, living biomass, enzymes, sorbents like industrial waste from breeding of mushrooms, chitosan, peat, and plant wastes may be utilized. A lot of attention is focused on fungal decolorization processes. These organisms are used as sorbents and/or enzymes producers for biodegradation/biotransformation. Most of studies are concentrated on dyes removal by single fungal strains (Banat et al. 1996; Azmi et al. 1998; Kumar Sani and Chand Banerjee 1999; Swamy and Ramsay 1999; Pointing and Vrijmoed 2000; Padamavathy et al. 2003; Forgacs et al. 2004; Deng et al. 2008; Przystaś et al. 2009; Zabłocka-Godlewska et al. 2012; Kwang-Soo 2004; Revankar and Lele 2007; Knapp et al. 1995; Wesenberg et al. 2003; Novotny et al. 2004; Gill et al. 2001; Reddy 1995). Significantly fewer studies are concentrated on decolorization by mixed fungal cultures (Ramalingam et al. 2010; Nascimento et al. 2011; Asgher et al. 2012). The main objective of our study is assessment of different dyes decolorization effectivity by fungal mixtures [Pleurotus ostreatus (BWPH) + Gloeophyllum odoratum (DCa) and P. ostreatus $+F u$ sarium oxysporum (G1)]. Zootoxicity and phytotoxicity of used dyes as well as process by-products were determined.

\section{Materials and Methods}

\subsection{Tested Organisms and Culture Conditions}

Fungal strains $P$. ostreatus, G. odoratum, and $F$. oxysporum (bankit1276596 544 bp DNA linear PLN 15-OCT-2009) were isolated with tissue method from fruit bodies taken from forest near Gliwice (south of Poland, Upper Silesia Region) on MEA (Fluka). Samples were incubated at $26{ }^{\circ} \mathrm{C}$. Cultures were maintained in MEA slants and stored at $4{ }^{\circ} \mathrm{C}$.

\subsection{Antagonisms Test}

Antagonistic interactions among strains used in experiment were tested on MEA (Fluka). Pieces of 5 days old cultures $(0.5 \times 0.5 \mathrm{~cm})$ were placed on Petri plate $(90 \mathrm{~mm})$ in equal distance between each other and the edge of the plate. Inhibition zones (the distance between growth zones of strains if it is observed) were measured after 7 days of incubation at $26{ }^{\circ} \mathrm{C}$.

\subsection{Decolorization Experiment}

Single strains and strains mixtures were used in experiment to compare effectiveness of different dyes decolorization. Mixtures were composed with strains selected on a base of antagonisms test (no inhibition effect). Cultures were grown in 300-mL flasks containing $150 \mathrm{~mL}$ of YEPG medium (glucose $10 \mathrm{~g} / \mathrm{L}$, peptone $5 \mathrm{~g} / \mathrm{L}$, yeast extract $2 \mathrm{~g} / \mathrm{L}, \mathrm{MgSO}_{4}$ $0.5 \mathrm{~g} / \mathrm{L}, \mathrm{KH}_{2} \mathrm{PO}_{4} 1 \mathrm{~g} / \mathrm{L}, \mathrm{pH}$ 5.6). Samples with single strains were prepared from two discs $(\varnothing 5 \mathrm{~mm})$ of 7 days mycelium on MEA (Fluka Biochemica) added to each flask. Mixed cultures were prepared by addition of one disc of each strain.

Water solutions of triphenylmethane dye brilliant green (POCh) and diazo dye Evans blue (Sigma-Aldrich) were filter sterilized (Millipore cellulose filters $\varnothing$ $0.20 \mu \mathrm{m}$ ) and added to 5 days old fungal cultures. Characteristic of both dyes is presented in Table 1. Final dyes concentrations in samples were the following: $0.06 \mathrm{~g} / \mathrm{L}$ of brilliant green, $0.15 \mathrm{~g} / \mathrm{L}$ of Evans blue, and $0.08 \mathrm{~g} / \mathrm{L}$ of dyes mixture (brilliant green and Evans blue 1:1 w/w). Control samples with dyes (without biomass) were prepared on sterile medium. Dead biomass was used for estimation of biosorption and was obtained by autoclaving for $15 \mathrm{~min}\left(121^{\circ} \mathrm{C}, 1.5 \mathrm{~atm}\right) 5$ days old cultures. All modifications (inoculated samples with/without dyes and samples with dead biomass with/without dyes) as well as controls were done quadrupled and shaken on a rotary shaker (100 rpm) at $26^{\circ} \mathrm{C}$ in order to maintain the same process conditions in all samples.

\subsection{Measurement of Decolorization Effectiveness and Samples Toxicity}

Absorbance was measured after 1, 6, 24, 48, 72, and 96 h (UV-VIS spectrophotometer Hitachi U1900). The wavelength for brilliant green $(624 \mathrm{~nm})$, Evans blue $(606 \mathrm{~nm})$, and dyes mixture $(591 \mathrm{~nm})$ was determined experimentally as the wave with maximal absorbance. Dyes mixture was examined at three wavelengths $(606,624$, and $591 \mathrm{~nm})$. Percentage dye removal was calculated according to the following formula:

$R(\%)=\frac{(C-S)}{C} \times 100 \%$

where $C$ is the current concentration of dye in a 
Table 1 Characteristic of used dyes

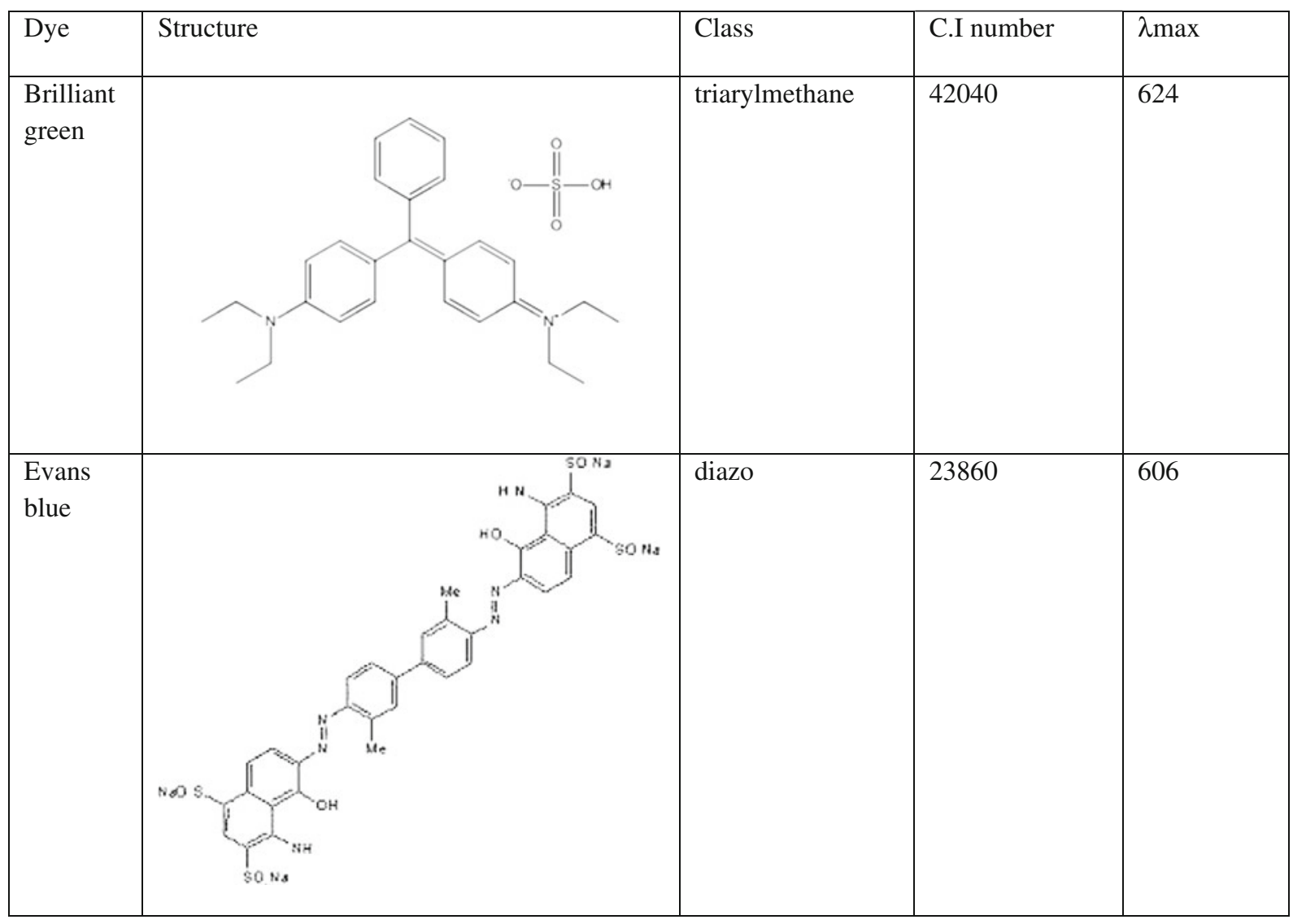

control sample (sterile medium with the dye or dyes mixture) (in milligram per liter), and $S$ is the current residue concentration of dye in samples with fungal biomass (in milligram per liter).

The zootoxicity was evaluated using Daphnia magna (OECD 202) and phytotoxicity using OECD Lemna sp. growth inhibition test (no. 221). Tests were done quadrupled. On the base of these information, acute toxicity unit $\left(\mathrm{TU}_{\mathrm{a}}\right)$ was calculated, and toxicity class was established.

$T U_{a}=\frac{100}{E C_{50}}$

$\mathrm{EC}_{50}$ is the effective concentration of a wastewater sample that causes an inhibition of test organism by $50 \%$. Samples were classified according to ACE 89/BE 2/D3 Final Report Commission EC $\left[\mathrm{TU}_{\mathrm{a}}<0.4\right.$, nontoxic (class I); $0.4 \leq \mathrm{TU}_{\mathrm{a}}<1.0$, low toxicity (class II); $1.0 \leq \mathrm{TU}_{\mathrm{a}}<10$, toxic (class III); $10 \leq \mathrm{TU}_{\mathrm{a}} \leq 100$, high toxicity (class IV); and $\mathrm{TU}_{\mathrm{a}}>100$, extremely toxic (class V)].

\section{Results and Discussion}

Biological processes of wastewater treatment (activated sludge and trickling filters) are based on the activity of microorganisms mixture. Mixed cultures seem to be the most effective for removal of variable concentration and unstable composition of dyes occurring in wastewater. In general, microorganisms' biodiversity promotes attack on the dye molecule at different positions as well as further decomposition of their byproducts. Su et al. (2009) proved that coculture of bacteria and fungi is more effective in azo dyes removal than single strains and suggested that it can be a good alternative for the field application. Advantage of coculture application is reduction of stress connected with high salinity of colored wastewater. 
Unfortunately, both mixtures used in the experiment were not so effective as we expected. Preparation of fungal mixtures was preceded by antagonisms test. No negative interactions and similar growth intensity were observed between strains BWPH/DCa and BWPH/G1. Inhibition zone was observed for strains DCa and G1, and the measured distance between colonies was $1.4 \mathrm{~cm}$.

Decolorization experiment was done in Erlenmeyer flasks. Dyes [Evans blue (EB), brilliant green (BG), or mixtures of both (GB)] were applied after 5 days of biomass incubation (BWPH $+\mathrm{DCa}$ and $\mathrm{BWPH}+\mathrm{G} 1)$. Initially, change of color and increase of absorbance were observed in these samples (Figs. 1, 2, 3, 4, 5 and 6). It can be the result of interaction between strains metabolites and dyes and/or stress connected with presence of another strain in culture. In samples with fungal mixture BWPH + DCa and brilliant green after $1 \mathrm{~h}$ of experiment, increase of color was more than $44 \%$ for living biomass and $58 \%$ for dead biomass (Figs. 1 and 4). After the same time, increase of absorbance in samples with Evans blue was more than 24 and $16 \%$, respectively (Figs. 2 and 5). Such deep increase was not observed in samples with single strains BWPH and DCa. It suggests that these strains produce some substances connected with presence of another strain in sample without growth inhibition effect. These metabolites probably interact with dyes. Increase of color was noticed also for mixture BWPH +
G1. After $1 \mathrm{~h}$ of experiment, color of samples with brilliant green was darker than that in controls (13.7\% for living biomass and $21.6 \%$ for dead biomass). In samples with Evans blue, increase of color was observed only in samples with living biomass $(6.3 \%)$.

Brilliant green was slightly removed by fungal mixtures, and process was probably based on adsorption on biomass (Fig. 1). After the end of experiment, decolorization reached $13.7 \%$ for culture BWPH + DCa and $7.8 \%$ for BWPH + G1. Single strains were more effective, and after $24 \mathrm{~h}$, color of samples with brilliant green was reduced in $\sim 53 \%$ for BWPH, $\sim 59 \%$ for DCa (living biomass), and $\sim 7 \%$ for G1. Living biomass of strain BWPH removed almost all color $(95.4 \%)$, G1 removed $75.9 \%$, and $\mathrm{DCa}$, only $64.8 \%$ of brilliant green after 96 h. Decolorization by strain DCa and G1 was based on adsorption of dye on biomass (not significant changes in dyes concentration between 1, 24, and $96 \mathrm{~h}$ of experiment). In case of BWPH, process was based not only on adsorption but also on biotransformation. Finally, brilliant green was adsorbed on dead biomass of BWPH in $35 \%$, DCa in $55 \%$, and on dead biomass of strain G1 in $73.1 \%$ (Fig. 4).

Removal of Evans blue (Fig. 2) was about $21 \%$ after $24 \mathrm{~h}$ and $43 \%$ after $96 \mathrm{~h}$ by living biomass of BWPH + DCa culture. Sorption on dead biomass was 14 and $19 \%$, respectively. In case of mixture BWPH + G1, only $9.8 \%$ of this dye was removed by living biomass
Fig. 1 Removal of brilliant green by living biomass of fungi

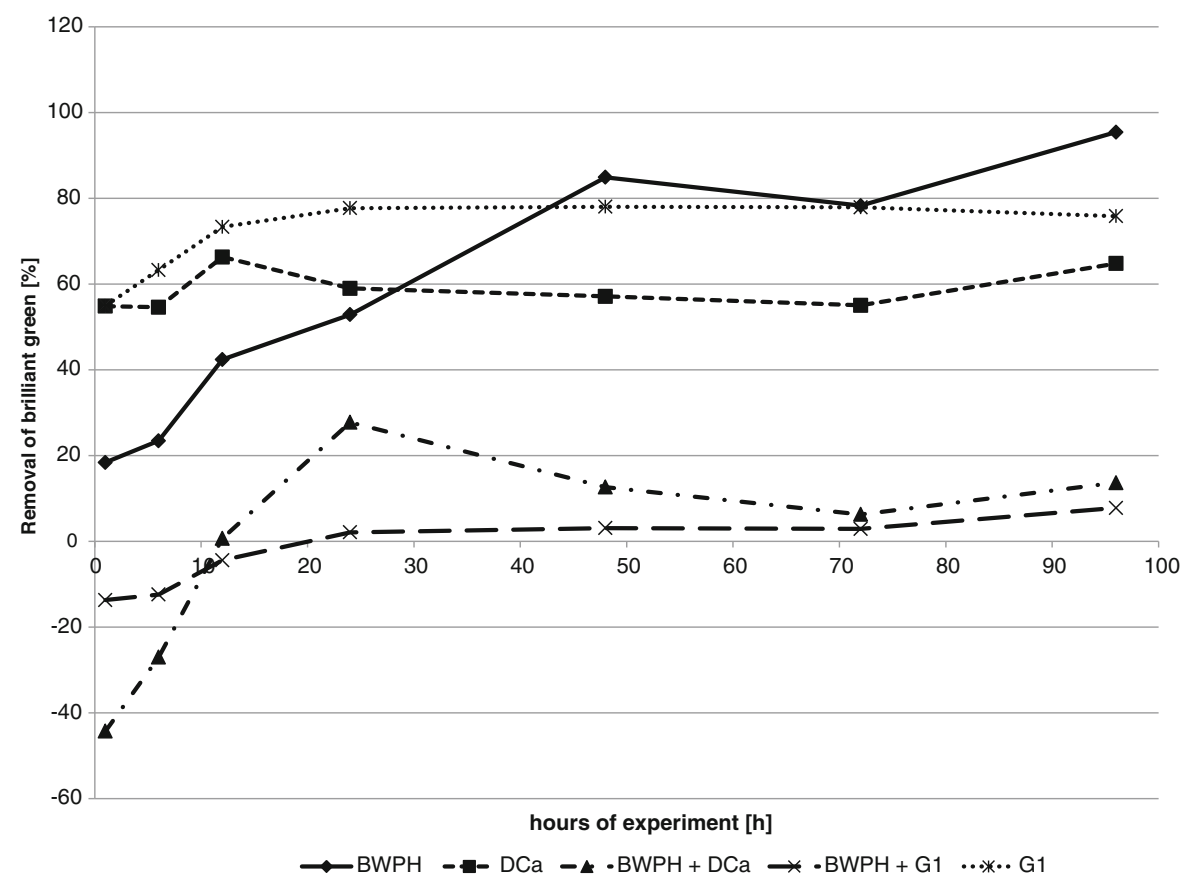


Fig. 2 Removal of Evans blue by living biomass of fungi

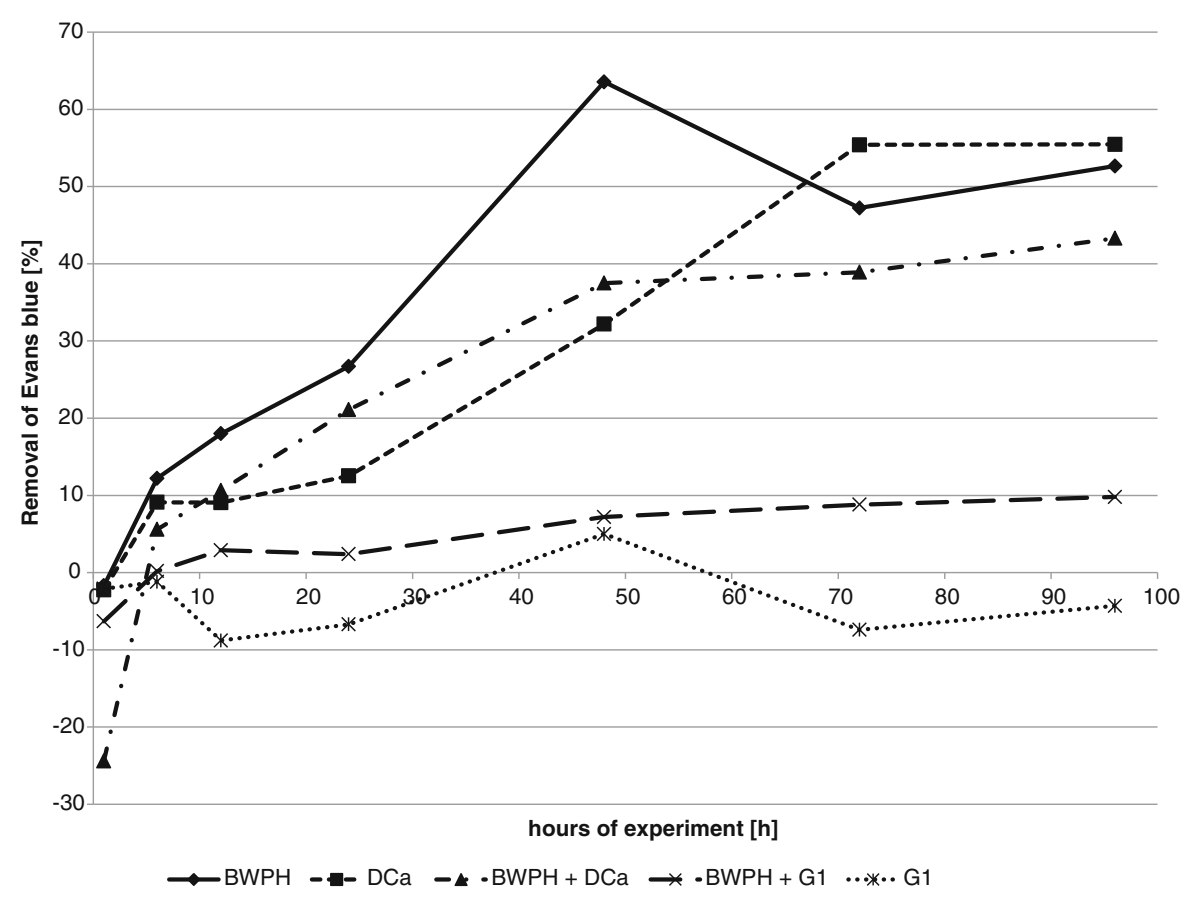

where dead biomass absorbed up to $42 \%$ after $96 \mathrm{~h}$ (Table 2; Fig. 5). Results reached for living mixed cultures were lower than those for single strains. Exception was strain G1 where no dye removal was noticed. Strains BWPH and DCa removed finally about $55 \%$ of dyes when the adsorption on dead biomass was less than
$10 \%$. Evans blue was almost completely absorbed by dead biomass of strain G1 (94.7\%). Efficiency of biosorption of pollutants is connected with specific for each species cell structure, mostly cell wall. Differences between results reached on dead and living biomass are related to changes of biomass properties after
Fig. 3 Removal of dyes mixture by living biomass of fungi

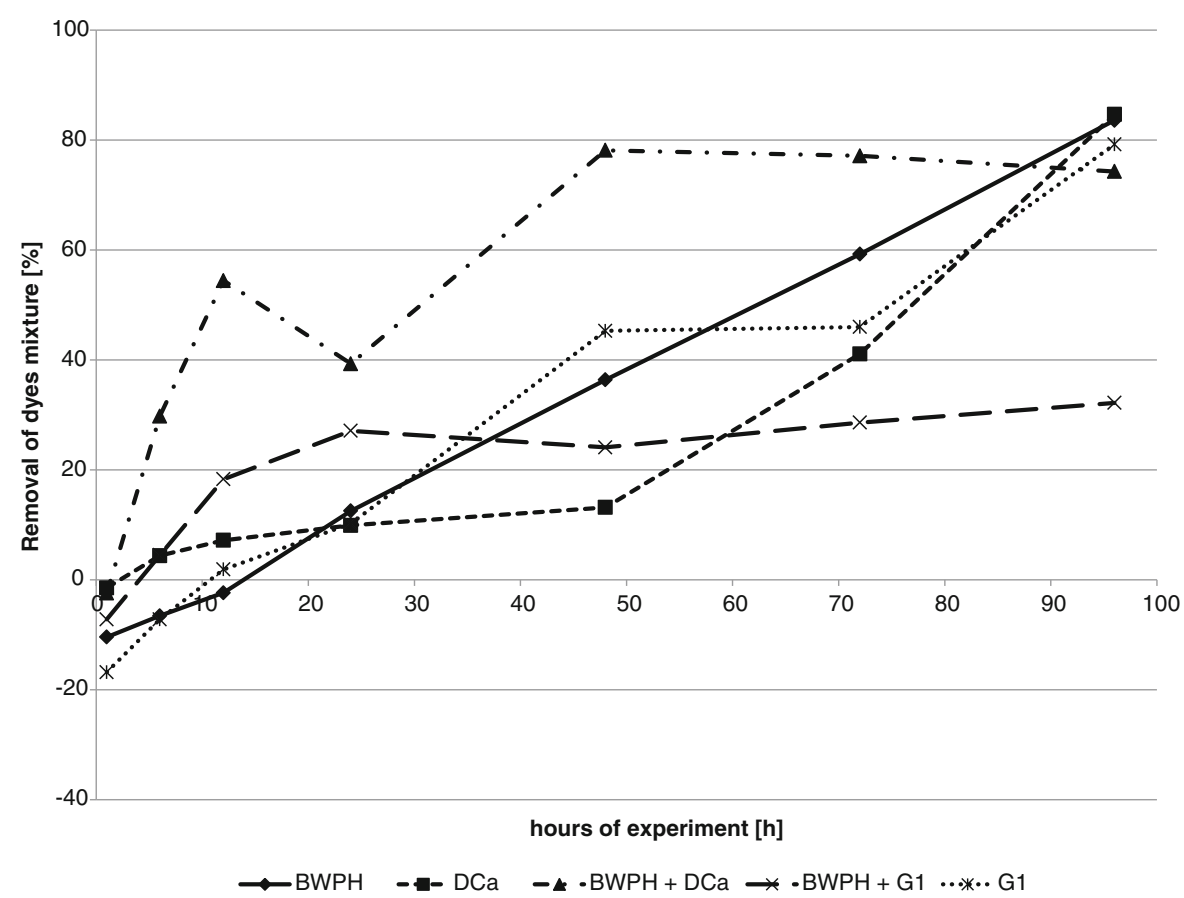


Fig. 4 Removal of brilliant green by dead biomass of fungi

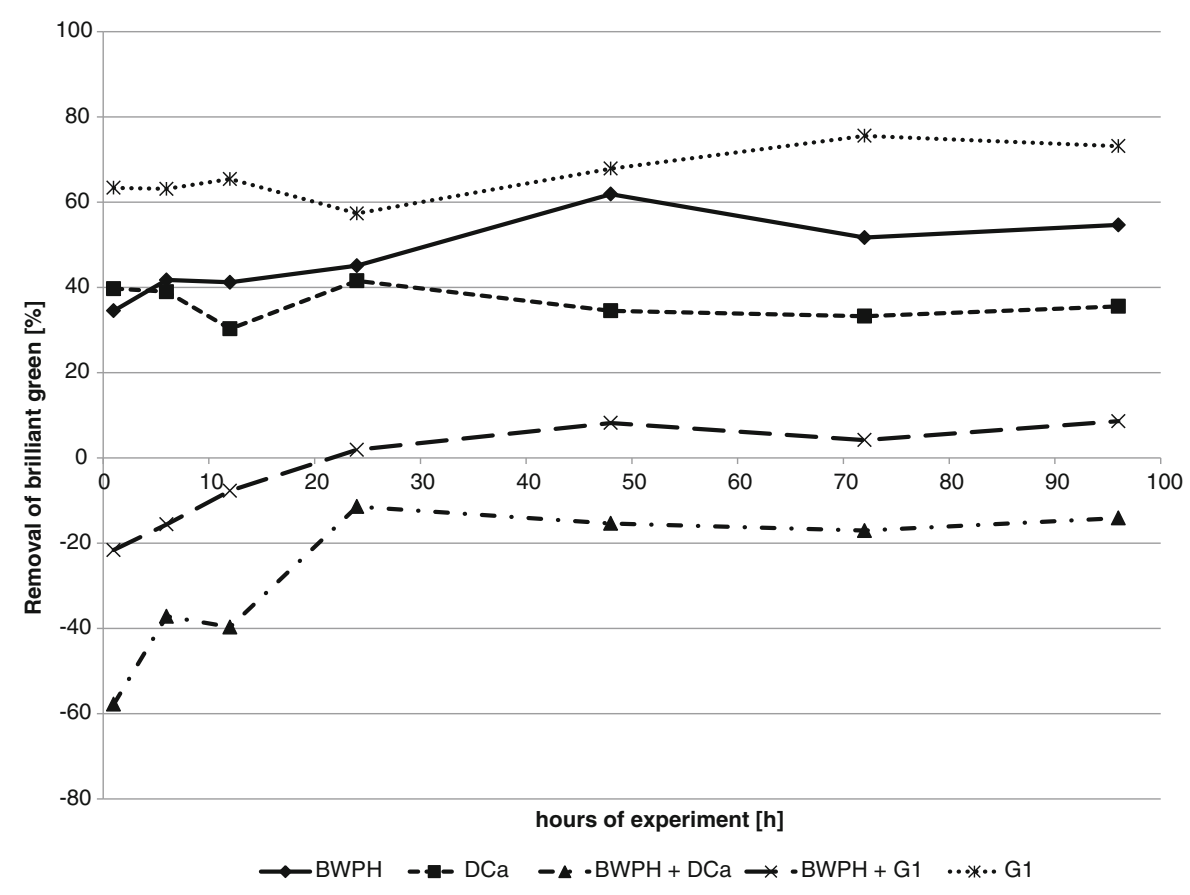

autoclaving. It is necessary to remember that thermal processes change physicochemical properties of biological material and have an influence on sorption properties (Zabłocka-Godlewska et al. 2012).

Removal of dyes mixture was determined at different wavelengths $(606,624$, and $591 \mathrm{~nm})$. In this paper, we present percentage removal determined only for
$591 \mathrm{~nm}$. Dyes mixture (GB) also was better removed by single strains than by mixed cultures (Table 2 ; Figs. 3 and 6). The same as for single dyes, their mixture was better removed by living than by dead biomass. At the end of experiment, removal of dyes mixture reached 83.6, 84.7, 79.2, 74.3, and $32.2 \%$ for BWPH, DCa, G1, BWPH + DCa, and BWPH + G1,
Fig. 5 Removal of Evans blue by dead biomass of fungi

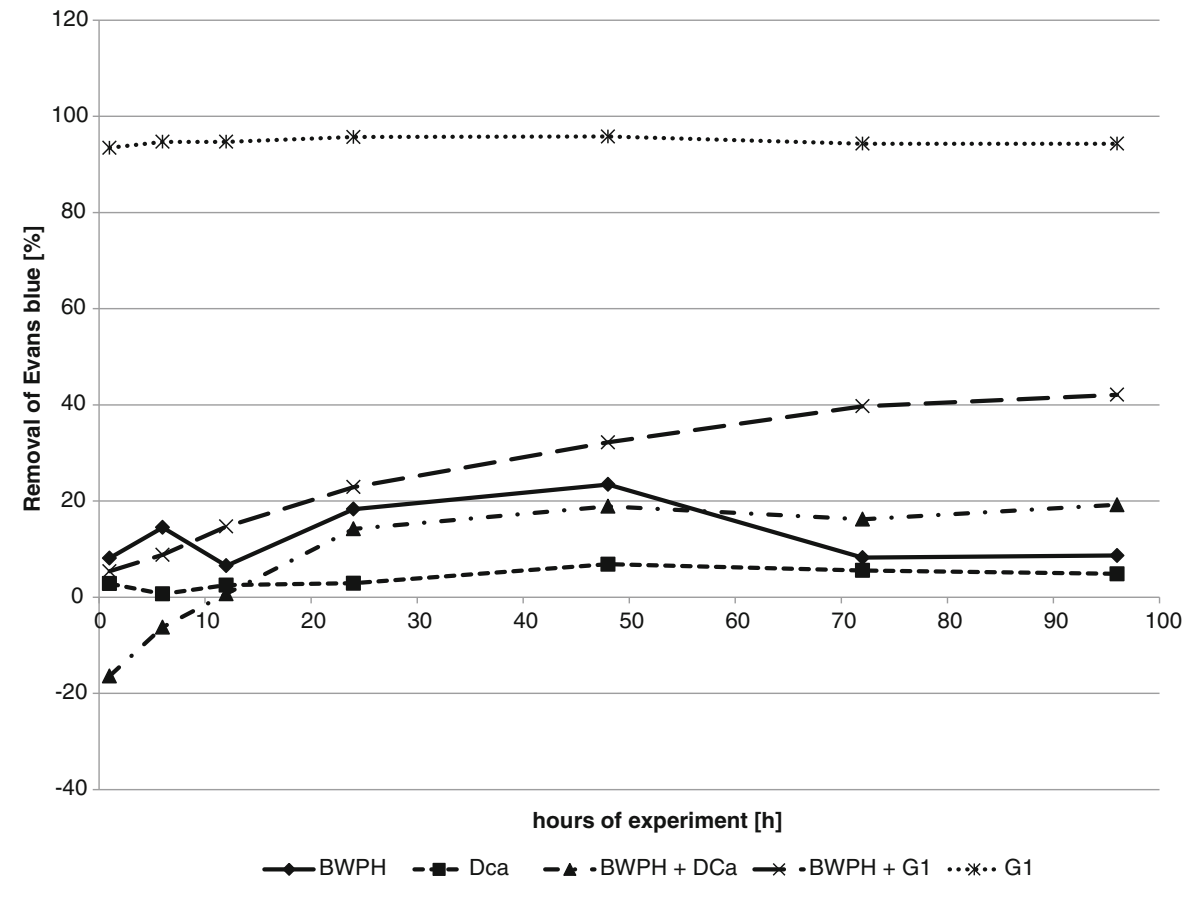


Fig. 6 Removal of dyes mixture by dead biomass of fungi

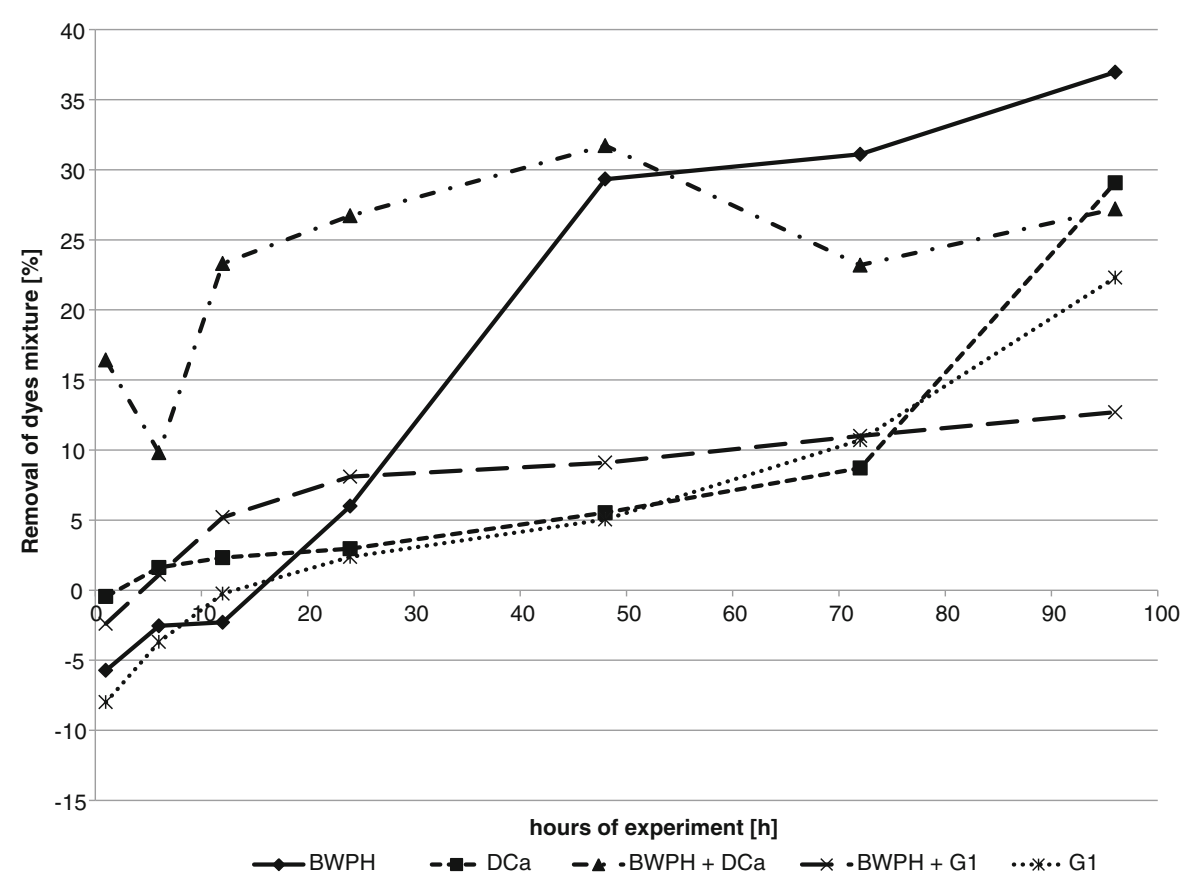

respectively. Such results are even three times higher than those reached in samples with dead biomass. In case of $\mathrm{DCa}$, results of decolorization by living biomass were even more than ten times higher than adsorption on dead mycelium.

Asgher et al. (2012) reached higher decolorization of industrial effluent by mixture of white rot fungi $P$. ostreatus and Coriolus versicolor (60.8\%) than by single strains $(\sim 52-53 \%)$. The authors suggest that better decolorization is an effect of combined action of three ligninolytic enzymes produced by different fungi. High dyes removal by mixed cultures of fungi was also reached by Nascimento et al. (2011), while some fungal consortia removed all Reactive Red 188 during 7 days.

Our results prove that sometimes, single strains are better choice for decolorization than mixed culture. The same tendency was noticed also by Ramalingam et al. (2010). They reached complete decolorization of Coomassie brilliant blue and $>90 \%$ decolorization of bromophenol blue after 20 days of experiment with Aspergillus tamari and Penicillium purpurogenum used as single strains. At the same, time strains mixture removed less than $80 \%$ of these dyes.

High effectiveness of dyes removal did not correspond with decrease of toxicity to D. magna and Lemna minor (Table 2). The same tendency for Daphnia pulex was reported by Nascimento et al. (2011). The highest decrease of zootoxicity was noticed for single strains
BWPH and G1 (from class V to III of toxicity or nontoxic for living as well as dead biomass and all dyes used in experiments). Zootoxicity in samples with strain DCa decreased to class III only for dyes mixture with living and dead biomass and in sample with dead biomass and Evans blue. In samples with strains, mixtures decrease of toxicity was lower (to class IV) or not noticed in sample with living biomass and Evans blue. In test with $L$. minor, decrease of toxicity was noticed also for samples with single strains of BWPH, G1, as well as DCa. No phytotoxicity was observed in samples with BWPH, brilliant green, and dyes mixture. No decrease of phytotoxicity was noticed in samples with mixed strains cultures. Samples without dyes with mixed cultures were classified as extremely toxic to $D$. magna and L. minor when controls with single strains were classified to class III or IV of toxicity (data not shown). This confirms that strains mixtures produce some toxic metabolites as a response to presence of the other strain in samples.

\section{Conclusions}

The results of the study show that in general, single fungal strains are more effective in dyes removal than their mixture. This is especially noticeable for brilliant green and living biomass used for decolorization. The 


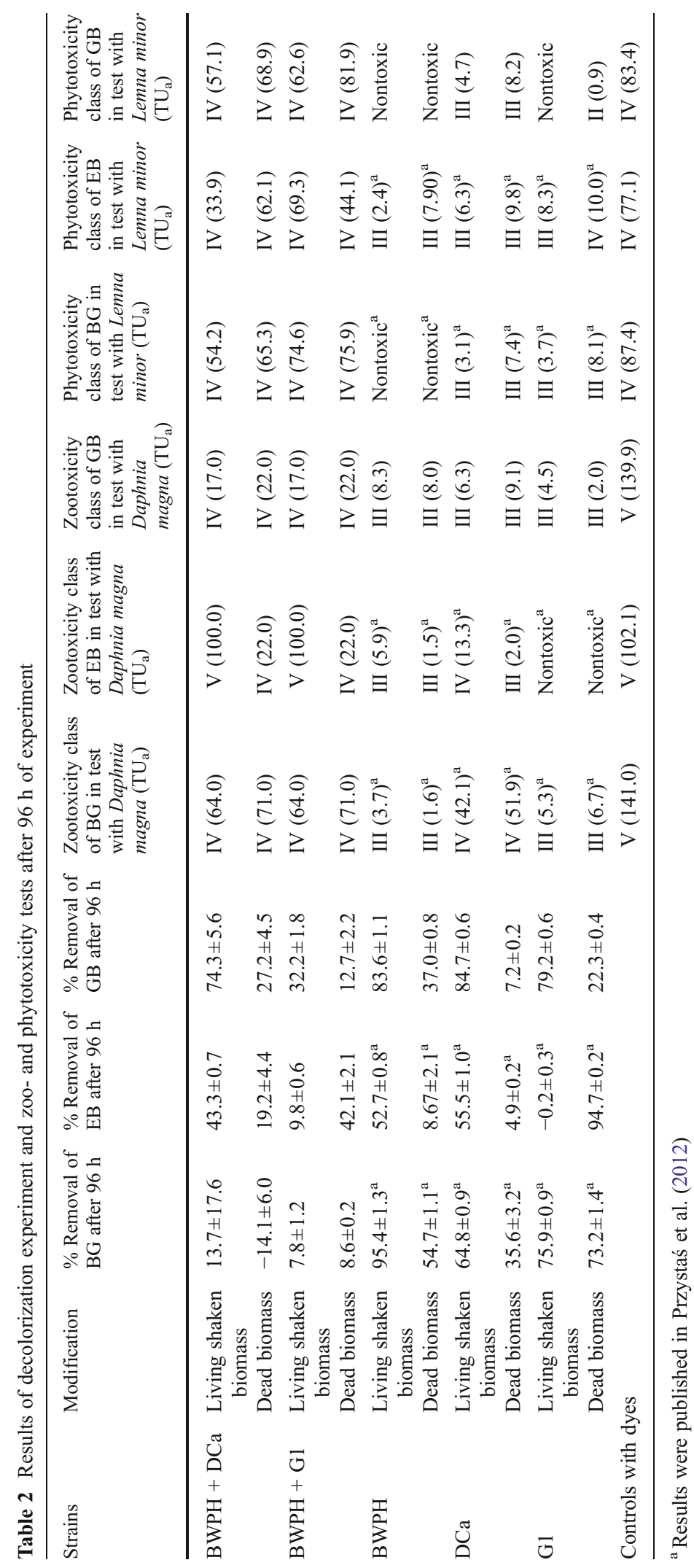


most effective strain P. ostreatus (BWPH) removed almost seven times higher concentration of this dye than used in mixture. Evans blue and dyes mixture were also more effectively decolorized by single strains. Coculture BWPH + DCa was more effective than single strains in dyes mixture removal at the beginning of experiment, but the final color reduction for both modifications reached about $80 \%$. High effectiveness of dyes removal did not correspond with decrease of toxicity to $D$. magna and L. minor. The highest decrease of zootoxicity and phytotoxicity was noticed for single strains, while no changes or slight toxicity decrease was noticed in samples with strains mixtures.

Acknowledgments This research has been supported by a grant from the Ministry of Science and Higher Education (2007-2010)_research project number N523 178533.

Open Access This article is distributed under the terms of the Creative Commons Attribution License which permits any use, distribution, and reproduction in any medium, provided the original author(s) and the source are credited.

\section{References}

Asgher, M., Jamil, F., \& Nasir Iqubal, H. M. (2012). Bioremediation potential of mixed white rot culture of Pleurotus ostreatus IBL-02 and Coriolus versicolor IBL-04 for textile industry wastewater. Journal of Bioremediation \& Biodegradation, S1, 007. doi:10.4172/2155-6199.

Azmi, W., Kumar Sani, R., \& Chand Banerjee, U. (1998). Biodegradation of triphenylmethane dyes. Enzyme and Microbial Technology, 22, 185-191.

Banat, I. M., Nigam, P., Singh, D., \& Marchant, R. (1996). Microbial decolorization of textile-dye-containing effluents: a review. Bioresource Technology, 58, 217-227.

Deng, D., Guo, J., Zeng, G., \& Sun, G. (2008). Decolorization of anthraquinone, triphenylmethane and azo dyes by a new isolated Bacillus cereus strain DC11q. International Biodeterioration \& Biodegradation, 62, 263-269.

Forgacs, E., Cserhati, T., \& Oros, G. (2004). Removal of synthetic dyes from wastewaters: a review. Environment International, 30, 953-971.

Fu, Y., \& Viraraghavan, T. (2001). Fungal decolorization of dye wastewater: a review. Bioresource Technology, 79, 251-262.

Gill, P. K., Arora, D. S., \& Chander, M. (2001). Biodecolorization of azo and triphenylmethane dyes by Dichomitus squalens and Phelbia spp. Journal of Industrial Microbiology and Biotechnology, 35, 377-391.

Knapp, J. S., Newby, P. S., \& Reece, L. P. (1995). Decolorization of wood-rotting basidiomycete fungi. Enzyme and Microbial Technology, 17, 664-668.

Kumar Sani, R., \& Chand Banerjee, U. (1999). Decolorization of triphenylmethane dyes and textile and dye-stuff effluent by Kurthia sp. Enzyme and Microbial Technology, 24, 433-437.
Kwang-Soo, S. (2004). The role of enzymes produced by whiterot fungus Irpex lacteus in the decolorization of the textile industry effluent. Journal of Microbiology, 41(1), 37-41.

Nascimento, C., et al. (2011). Degradation and detoxification of three textile azo dyes by mixed fungal cultures from semiarid region of Brazilian Northeast. Brazilian Archives of Biology and Technology, 54(3), 621-628.

Novotny, C., Svobodova, K., Kasinath, A., \& Erbanova, P. (2004). Biodegradation of synthetic dyes by Irpex lacteus under various growth conditions. International Biodeterioration \& Biodegradation, 54, 215-223.

Padamavathy, S., Sandhya, S., Swaminathan, K., Subrahmanyam, Y. V., \& Kaul, S. N. (2003). Comparison of decolorization of reactive azo dyes by microorganisms isolated from various source. Journal of Environmental Sciences, 15, 628-632.

Pointing, S. B., \& Vrijmoed, L. L. P. (2000). Decolorization of azo and triphenylmethane dyes by Pycnoporus sanguineus producing laccase as the sole phenoloxidase. World Journal of Microbiology and Biotechnology, 16, 317-318.

Przystaś, W., Zabłocka-Godlewska, E., \& Grabińska-Sota, E. (2009). Screening of dyes decolorizing microorganisms strains. Polish Journal of Environmental Studies, 18(2B), 69-73.

Przystaś, W., Zabłocka-Godlewska, E., \& Grabińska-Sota, E. (2012). Biological removal of azo and triphenylmethane dyes and toxicity of process by-products. Water, Air, and Soil Pollution, 223, 1581-1592.

Ramalingam, N., Saraswathy, N., Shanmugapriya, S., Shakthipriyadarashini, S., Sadasivam, S., \& Shanmugaprakash, M. (2010). Decolorization of textile dyes by Aspergillus tamari, mixed fungal culture and Penicillium purpurogenum. Journal of Scientific and Industrial Research, 69, 151-153.

Reddy, A. (1995). The potential for white-rot fungi in the treatment of pollutants. Current Opinion in Biotechnology, 6, 320-328.

Revankar, M. S., \& Lele, S. S. (2007). Synthetic dye decolorization by white rot fungus, Ganoderma sp. WR-1. Bioresource Technology, 98, 775-780.

Robinson, T., McMullan, G., Marchant, R., \& Nigam, P. (2001). Remediation of dyes in textile effluent: a critical review on current treatment technologies with a proposed alternative. Bioresource Technology, 77, 247-255.

Somasiri, W., Ruan, W., Xiufen, L., \& Jian, C. (2006). Decolorization of textile wastewater containing acid dyes in UASB reactor system under mixed anaerobic granular sludge. Electronic Journal of Environmental, Agricultural and Food Chemistry, 5(1), 1224-1234.

Su, Y. Y., Zhang, Y. F., Wang, J., Zhou, J. T., Lu, X. B., \& Lu, H. (2009). Enhanced biodecolorization of azo dyes by coimmobilized quinone-reducing consortium and anthraquinone. Bioresource Technology, 100, 2982-2987.

Swamy, J., \& Ramsay, J. A. (1999). The evaluation of white-rot fungi in the decoloration of textile dyes. Enzyme and Microbial Technology, 24, 130-137.

Wesenberg, D., Kyriakides, I., \& Agathos, S. N. (2003). Whiterot fungi and their enzymes for the treatment of industrial dye effluents. Biotechnology Advances, 22, 161-187.

Zabłocka-Godlewska, E., Przystaś, W., \& Grabińska-Sota, E. (2012). Decolorization of diazo Evans blue by two strains of Pseudomonas fluorescens isolated from different wastewater treatment plants. Water, Air, and Soil Pollution, 223(8), 5259-5266. 